
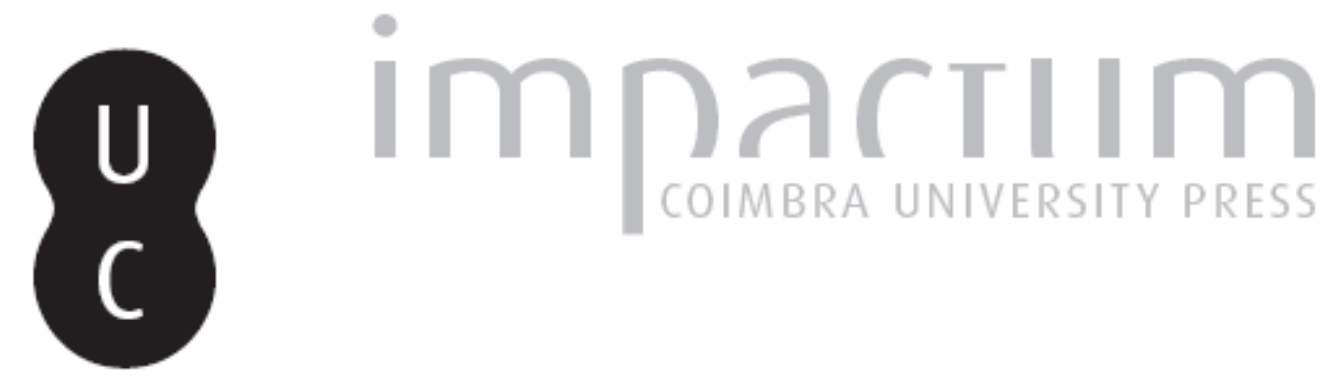

A Antígona da companhia chilena Los Mismos: uma tragédia contemporânea

Autor(es): $\quad$ Castro Filho, Claudio

Publicado por: $\begin{aligned} & \text { Associação Portuguesa de Estudos Clássicos; Instituto de Estudos } \\ & \text { Clássicos }\end{aligned}$

URL

persistente:

URI:http://hdl.handle.net/10316.2/30452

DOI:

DOI:http://dx.doi.org/10.14195/0872-2110_51_16

Accessed : $\quad$ 26-Apr-2023 15:49:13

A navegação consulta e descarregamento dos títulos inseridos nas Bibliotecas Digitais UC Digitalis, UC Pombalina e UC Impactum, pressupõem a aceitação plena e sem reservas dos Termos e Condições de Uso destas Bibliotecas Digitais, disponíveis em https://digitalis.uc.pt/pt-pt/termos.

Conforme exposto nos referidos Termos e Condições de Uso, o descarregamento de títulos de acesso restrito requer uma licença válida de autorização devendo o utilizador aceder ao(s) documento(s) a partir de um endereço de IP da instituição detentora da supramencionada licença.

Ao utilizador é apenas permitido o descarregamento para uso pessoal, pelo que o emprego do(s) título(s) descarregado(s) para outro fim, designadamente comercial, carece de autorização do respetivo autor ou editor da obra.

Na medida em que todas as obras da UC Digitalis se encontram protegidas pelo Código do Direito de Autor e Direitos Conexos e demais legislação aplicável, toda a cópia, parcial ou total, deste documento, nos casos em que é legalmente admitida, deverá conter ou fazer-se acompanhar por este aviso.

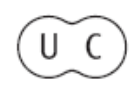




\section{Boletim de}

\section{Estudos Clássicos}

Associação Portuguesa de Estudos Clássicos Instituto de Estudos Clássicos

Coimbra

Junho de 2009 


\title{
A antígona da Companhia Chilena los Mismos: UMA TRAGÉDIA CONTEMPORÂNEA
}

\author{
"A intertextualidade torna-se o movimento essencial na escrita \\ que transpõe enunciados anteriores ou contemporâneos, e \\ aparece através da alusão, da paródia, do pastiche e de todos \\ os tipos de reminiscência e reescritura" (C. Massa 2008: 47).
}

Uma dupla de irmãos gêmeos adentra o palco (estão vestidos de modo análogo e desempenham gestos roboticamente semelhantes) e dirige-se ao proscênio, onde um fragmento de coluna grega (ou melhor, uma imitação em gesso) ocupa lugar de destaque. Um deles traz um substante pedaço de carne crua; o outro, uma garrafa big de Coca-Cola. Está iniciado o sacrifício: a carne é depositada num recipiente plástico e embebida pelo letal refrigerante. O público, ao longo de todo o espetáculo que ali se anuncia, acompanhará o acelerado e espontâneo processo de cozimento e putrefação da carne pelo simbólico ácido, a testemunhar, com os próprios sentidos, a ação provocada pelo mesmo trágico licor em nossos estômagos. É com este acentuado requinte de referências e provocações que se inicia o espetáculo "Antígona", de Felipe Serrano, dramaturgo e encenador da Compañía de Investigación Teatral Los Mismos, que esteve em cartaz no Instituto Cultural Montecarmelo, em Santiago do Chile, entre 27 de setembro e 21 de outubro de 2008.

A longa e necessária descrição que aqui inicio, é preciso dizer, tem como pressuposto, no referido espetáculo, a total continuidade entre texto e cena. Ou seja, na "Antígona” encenada pelo grupo Los Mismos não é possível dissociar a materialidade da cena - e todos os códigos poéticos ali estabelecidos - da urdidura dramatúrgica a ela correspondente. Estamos diante, portanto, de um acontecimento teatral consciente da interdependência entre a fala e a ação, entre o logos e a opsis, entre a narratividade e a visualidade. Tomando o conjunto texto-cena, nesta singular "Antígona", como produção de discurso por excelência (seja ele verbal ou não), pode-se falar mesmo de uma 'dramaturgia-encenação' assinada por Serrano, tendo em vista que tal autoria remete tanto ao texto (ou seja, à peça) quanto à direção 
cênica (isto é, ao espetáculo em si). Não se trata, porém, de mera questão de assinatura, mas da elaboração de uma complexa discursividade, na qual, grosso modo, o que se vê no palco corresponde à componente didascálica daquilo que se diz em cena.

Os dois artificiosos rapazes, será revelado depois, chamam-se Mateo e Matias, dois jovens 'capangas' do tele-novelesco empresário Creonte. O prólogo já descrito deixa claro que Mateo e Matias desempenham, no drama, papel equivalente ao do coro grego, tendo em vista serem eles os que despoletam o irônico rito sacrificial que abre o espetáculo. Mas nesta talvez anti-trágica releitura, os signos da tragédia ática são incorporados sob o rascante tom da derrisão: não é mais em honra de Dioniso, deus ébrio da fertilidade e das inversões carnavalizantes, que se sacrifica a carne, mas em honra do poder corrosivo que o moderno capitalismo exerce sobre o homem. Além disso, se o coro grego era formado por cidadãos cujas identidades se imiscuíam em prol do bem-estar coletivo, aqui, as identidades se robotizam, se padronizam em função dos hábitos de consumo e do fetichismo que objetualiza o próprio sujeito. Os atléticos Mateo e Matias cairão pouco depois num sedutor jogo proposto pela colegial Ismene, jovem que, em pleno exercício de sua puberdade, fantasia entregar-se aos gêmeos cujas identidades ela confunde, tamanhas as semelhanças das feições e atitudes entre os dois. E é ao disputar o amor (ou a virgindade) de Ismene que Mateo e Matias levam quase ao extremo a patologia que atravessa a exacerbada semelhança entre os dois - semelhança, ressalte-se, artificialmente construída pelo bem cuidado trabalho de atores, direção e desenho de figurinos. Reverbera, na disputa amorosa travada entre os gêmeos, a própria disputa que dá, desde o mito sofocliano, as condições de instauração da tragédia, ou seja, a disputa alelofágica entre Polinice e Etéocles.

Ismene e Creonte aparecem nesta livre versão como estereótipos da colegial sedutora (uma lolita), no caso dela, e do capitalista especulador, no caso dele. Cria-se, assim, uma polaridade com a qual Antígona terá de se confrontar: de um lado, a dúvida, a hesitação da irmã que teme a norma; de outro, a soberba e a tirania sobrelevadas na fusão dos poderes econômico e político do empresário-rei. O caminho aparentemente superficial de lidar com os estereótipos revela-se, na 'dramaturgia-encenação' de Serrano, uma escolha sagaz, já que essa estranha polaridade pode ser interpretada como desdobramento dos próprios conflitos internos - de ordem afetiva, psicológica, ética, mágica - com que se depara Antígona, a protagonista do drama. De um lado, a fragilidade e a dúvida adolescentes; de outro, a 
cegueira em face de tudo que contrarie a própria convicção. Não é justo nessa ambiguidade (desmembrada na polaridade Ismene-Creonte) que reside a psique da própria Antígona?

Ainda tratando da questão da estereotipia, vale destacar o quão curiosa soa ao espectador contemporâneo a leitura proposta por Serrano para a figura de Creonte. O poder político do tirano sofocliano é, como já dito, equiparado ao poder financeiro do capitalista moderno. A mordacidade da leitura está em identificar o caráter parasitário do empresário-rei, que corporifica, no espetáculo em questão, o caráter especulativo do setor financeiro à diferença do caráter produtivo do setor econômico. Ou seja, se a economia contemporânea fundamenta-se, por um lado, no trabalho e no consumo dos produtos daí gerados (que, em última instância, servem ao bem-estar individual), o desdobramento financeiro do capitalismo dito pós-moderno, ainda que vinculado à economia, revela seu caráter especulativo numa figura de poder que somente é vista em cena ocupando o próprio ócio: jogando golf, refrescando-se com um refrigerante, fazendo sua sauna - eis as "ações" executadas por Creonte na leitura de Serrano. Desdenha-se, assim, da visão canônica de ação dramática (que, pelo menos desde Aristóteles, é um dos fundamentos que movem a trama, o mythos), ganhando, agora, uma leitura política que nos convoca a refletir sobre os valores que fundamentam, ou que ao menos justificam, o poder e seu respectivo exercício no mundo de hoje.

Ainda sobre este peculiar Creonte, é preciso registrar algo que imediatamente ocorreu a meu olhar de espectador estrangeiro e que diz respeito à ridicularização de uma emblemática figura de poder no contexto histórico chileno. É ainda uma ferida aberta, na memória do povo chileno, a questão da ditadura militar que usurpou a presidência do país entre 1973 e 1989 e personificou-se na figura do general Augusto Pinochet, que esteve à frente da presidência durante toda a vigência do regime autoritário. $\mathrm{O}$ poder ditatorial ganhou, ali, uma cara que, aos olhos de uma produção artística atenta às questões democráticas, não pode ser representada senão com traços caricaturais, com feições risíveis. O compromisso político (para não usar o termo "engajamento", já bastante estigmatizado) do grupo Los Mismos, faz-se mister mencionar, é uma de suas marcas, tendo em vista que, até a presente encenação, a companhia dedicava-se integralmente a levar atividades teatrais para comunidades de poucos recursos.

Ao ridicularizar Creonte ridiculariza-se, portanto, a figura de Pinochet e, na esteira, todo poder ditatorial. Tal propósito encontra aqui um instigante desafio para a encenação: se, de um lado, a sátira política fortalece 
ideologicamente a dramaturgia-encenação de Serrano, de outro, enfraquece a potência contra a qual se opõe Antígona. Como crer numa tragédia cujo antagonista tangencia a bufonaria? É possível manter acesa a vigência do trágico em tal contexto?

Se nos ativermos a Creonte, é possível que as respostas para tais perguntas tendam ao negativo. Mas é aí que entra a contundência arquetípica de Antígona, caracterizada por Serrano como a voz da própria terra que quer sepultar o injustiçado Polinice, resgatando a dimensão trágica fortemente presente no espetáculo. Ao ser questionada sobre a razão que a fazia acreditar ser capaz - ela, uma moça ainda tão jovem e, supostamente, frágil - de contrariar as ordens do poderoso tio, Antígona, nesta versão, contesta que a força de suas lágrimas pôde fazer renascer as flores secas do deserto.

A metáfora das lágrimas que irrigam e, assim, semeiam a terra, superando inclusive a secura do ermo, dá a medida simbólica da força trágica de que se imbui a Antígona de Serrano, a herdar, pois, elementos arquetípicos que a vinculam com suas origens gregas. Como bem nota a crítica teatral Maria Lúcia Candeias (2006: 81), referindo-se ao texto de Sófocles, “ela quer enterrar o irmão a todo e qualquer custo, enfrentando com coragem assombrosa as ordens do chefe de estado. É presa, mas desperta a solidariedade de todos os conterrâneos".

Do ponto de vista do respeito aos cânones dramáticos, porém, o diálogo entre a "Antígona" de Felipe Serrano e sua inspiração sofocliana dá-se de maneira absolutamente livre, de tal modo que sua poética, fruto já de uma prática teatral em consonância com estéticas ditas contemporâneas, permite realcançar a dimensão mítica de outrora, porém por caminhos próprios, traçados com a singularidade do processo criativo do grupo. A companhia Los Mismos assim descreve seu espetáculo e seu processo de criação para "Antígona":

"Es una puesta en escena que busca rescatar la belleza de las palabras, y al mismo tiempo conjugar el texto con elementos escénicos que resalten la naturaleza trágica de la obra. La acción transcurre en una escena vacía y silenciosa, donde los roles son los únicos habitantes de esta tierra olvidada que es testigo de la narración de una fábula sobre los gobernantes de una patria. El trabajo escénico se basa en la opinión de cada actor sobre el escenario, dando libertad a cada uno de ellos para que el texto surja de su propia necesidad y no de cánones preestablecidos. Los roles son construidos desde la biografía escénica, es decir desde la experiencia real e irrepetible que 
cada actor ha vivido durante los ensayos. La puesta en escena, finalmente, persigue evidenciar el trabajo del actor como la búsqueda del rol en el nexo entre la dramaturgia propuesta y la biografía de sí mismo"1.

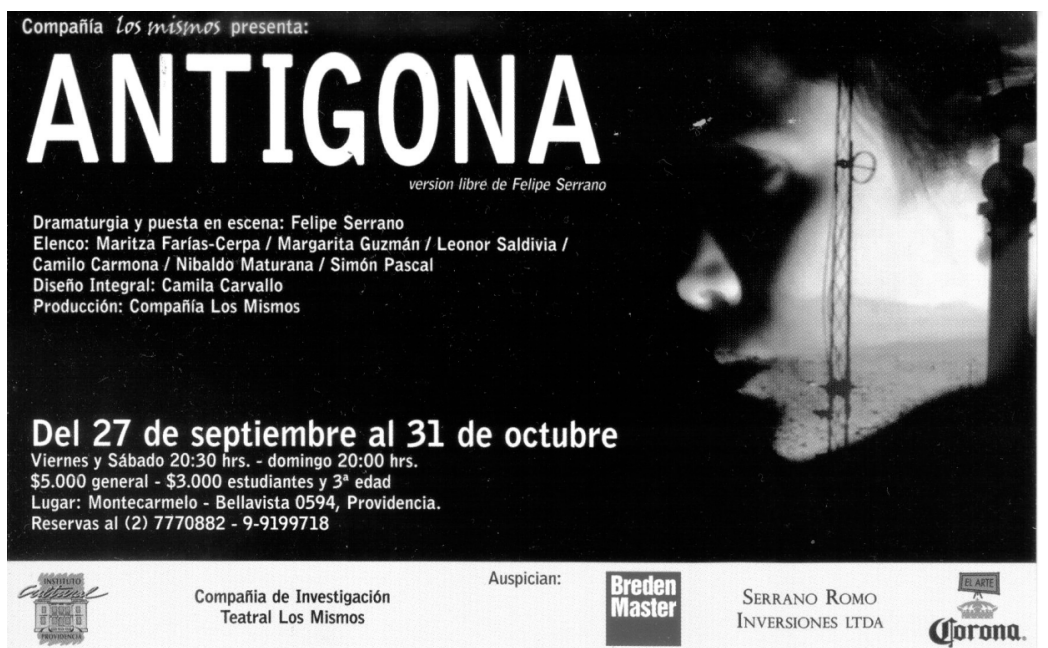

O resultado de tal processo, pautado na leitura individualizada de cada ator em face do mito, aponta para um texto e uma cena de forte caráter vanguardista (conforme fazem notar as descrições até aqui apresentadas). Porém, isso não significa, para Los Mismos, atingir o hermetismo de uma dramaturgia pós-becketiana, mas construir uma cena livre de rótulos classificatórios e que pode, portanto, transitar sem culpa entre o antigo e o contemporâneo. Para focar num único aspecto, tanto podemos ler as personagens como desconstruções, leituras distanciadas de cada ator em face da persona mítica por ele investigada, como podemos acreditar na existência dramática daquela figura, tendo em vista a contundência simbólica que o recurso ao mito grego propicia. Grosso modo, quanto mais Serrano e seus atores - Maritza Farías-Cerpa, Margarita Guzmán, Leonor Saldivia, Camilo Carmona, Nibaldo Maturana, Simón Pascal - se sentem livres da "Antígona" de Sófocles, mais próximos do texto grego eles parecem chegar. Trata-se,

1 "Antígona en Montecarmelo", in http://areateatro.blogspot.com, acessado em 10 de dezembro de 2008. 
portanto, de uma espécie de paradoxo em que construção e desconstrução do discurso se dão no entrecruzamento de referências que dialogam, mediante produtivas tensões, sem qualquer hierarquia. Como observa Hans-Thyes Lehmann (2007: 247), "o que caracteriza o novo teatro, assim como as tentativas radicais da 'linguagem poética' dos modernos, pode ser entendido como tentativa de restituição da chora: de um espaço e de um discurso sem télos, hierarquia, causalidade, sentido fixável e unidade".

É evidente que, ao retomar a narrativa grega - partindo de um texto, "Antígona", ainda bastante presente em nosso imaginário cultural -, Serrano está longe de recorrer a radicalismos gratuitos. Por outro lado, a disposição criativa do grupo chileno para reinventar o mythos sofocliano é de fato grande, o que fica finalmente perceptível com a inclusão, para não dizer ressurreição, de uma personagem que, assim, provoca um verdadeiro embaralhamento das relações temporais que (mediante a aristotélica continuidade entre princípio, meio e fim) davam sentido ao mito dos Labdácidas. Refiro-me, agora, à figura de Jocasta, incluída, na leitura de Serrano, como rainha, ao lado de Creonte.

Em termos narrativos, portanto, a Jocasta de Serrano substitui Eurídice, esposa de Creonte na obra de Sófocles, aqui suprimida tal e qual seu filho Hémon. Ao recontextualizar, sem dúvida ironicamente, a presença de Jocasta no mito, Serrano torna a questão trágica dos Labdácidas ainda mais patológica, se considerarmos os desdobramentos psicanalíticos que a tragédia grega tomou no mundo moderno, ao servir de ponto de partida para as interpretações freudianas da psique humana. Esta nova Jocasta acumula, então, múltiplos parentescos com a protagonista do drama - ela é, ao mesmo tempo, avó, mãe e tia de Antígona. Sugere-se, além disso, o incestuoso casamento de Jocasta com Creonte, que, sabemos, é seu irmão na árvore labdácida. Demarca-se, assim, uma verdadeira promiscuidade genealógica, dando à trágica casta uma feição quase rodrigueana, tamanha a inverossimilhança que marca o absurdo de tais 'laços de família'.

Na montagem de Los Mismos, a composição de Jocasta é, sem exagero, o mais instigante dos trabalhos de atuação. Dada a avançadíssima idade da personagem, ela se torna uma espécie de porta-voz oracular do mito sofocliano, a testemunhar a decadência que, geração a geração, marca aquela família. Considerando a leitura política proposta pelo grupo, é possível afirmar que a decrepitude desta Jocasta é não só a decrepitude dos Labdácidas, mas a decadência do próprio imperialismo (ou seja, da hegemonia norte-americana, dos governos ditatoriais latino-americanos, do 
monopólio das grandes corporações etc.) no mundo contemporâneo. Jocasta arrasta-se com um vestido longo cujo luxo, típico de ocasiões festivas, tornase ainda mais desbotado num corpo envelhecido, trêmulo e arqueado, que já não corresponde à silhueta ideal para aquele traje. A decadente rainha traz ainda perucas coloridas cujos penteados parecem ser a única ocupação de sua existência ociosa, a aguardar a morte e a portar a memória de todas as venturas e, principalmente, tragédias que marcaram o passado de sua outrora nobre família.

O que está em jogo, então, nesta "Antígona" cuja sardônica ironia não mais aposta nos valores religiosos, psicológicos e morais que perpassaram a obra original de Sófocles e que inspiraram tantas de suas releituras? É possível encontrar nesta leitura contemporânea um subsídio forte o suficiente para balizar os argumentos de Antígona, que quer sepultar o irmão à revelia das ordens estatais, e de Creonte, que quer a qualquer preço impor a autoridade de seu cargo? Talvez o que fundamente o ímpeto, a falsa-certeza, a cegueira de Antígona e Creonte em face de tudo o que lhes desafie a própria convicção seja, exatamente, o esvaziar de seus fundamentos, não mais comprometidos com o peso trágico correspondente à versão sofocliana. Por outro lado, não posso deixar de sublinhar que a beleza poética do texto de Serrano aponta não só para a crise de fundamentos da cultura contemporânea, mas para a nossa desesperada busca por reatar os laços da humanidade com valores éticos (aqui desdobrados em construções estéticas) que nos permitam uma visão não apocalíptica do futuro. Ainda que ligeiramente utópica, a convicção de Antígona com a verdade dos sentimentos que lhe vinculam com seu irmão e com sua terra aponta para a imperiosa necessidade de se lutar por uma causa como caminho para um ser humano que quer marcar sua singularidade justo ao afirmar seu comprometimento com o respeito à diferença. Numa leitura ética, ou até mesmo política, trata-se do acolhimento das diferenças de etnia, de gênero e sexualidade, de crença religiosa, de visões políticas, de concepções estéticas.

Ao transplantar para o deserto contemporâneo (cuja secura prenuncia o futuro cataclismático do planeta, mas cujo subsolo e ecossistemas guardam também a riqueza que a humanidade cobiça) uma heroína arquetípica como Antígona, Felipe Serrano toca na questão fundamental que nos convoca ao diálogo universal: estamos todos expostos à mesma irremediável certeza, a certeza da finitude, da morte. A despeito de qualquer fronteira (geopolítica, socioeconômica, etc.), a humanidade habita um mesmíssimo deserto. Não se encontra aqui nosso destino trágico? É possível uma ação política outra que 
não a de extravasar a própria loucura num aliviante gole de refrigerante gelado, como fazem todos os personagens-atores no decorrer da encenação do grupo Los Mismos? Não estaria este gole a nos carcomer por dentro, tal e qual relembra o rito sacrificial que impulsiona o espetáculo?

É interessante notar que Hans-Thyes Lehmann (2007), ao abordar problemas desta ordem, vai buscar justo na filosofia os argumentos que legitimam suas observações acerca da pós-dramaticidade que caracteriza boa parte da produção teatral contemporânea. Entre os autores privilegiados em sua leitura, chama a atenção a presença de Jacques Derrida, filósofo francoargelino que alavancou uma das mais impactantes correntes filosóficas da segunda metade do século XX, a chamada 'teoria da desconstrução'. No rastro de tal perspectiva, a presença do mito na cultura contemporânea é pensada não meramente como herança recebida dos antigos, mas justo como possibilidade de desconstrução da lógica predominante na cultura ocidental, qual seja, a lógica da razão cientificista. A filosofia, entendida dentro de uma perspectiva metafísica, é, desde Platão, o lugar por excelência onde a razão consolidará sua hegemonia em face de tudo aquilo que diga respeito aos seus díspares, suas diferenças, como a sensibilidade, a intuição, os afetos corpóreos etc. $\mathrm{O}$ mito, ao desestabilizar a lógica racional, propicia a desautorização da ideia de uma verdade absoluta, imutável, permanente. Pelo contrário, se há uma lógica no mito, trata-se de uma lógica da ambiguidade, da mutabilidade, da subversão dos valores.

"O mito coloca, então, em jogo uma forma de lógica que se pode chamar, em contraste com a lógica de não-contradição dos filósofos, uma lógica do ambíguo, do equívoco, da polaridade. Como formular, ou até mesmo formalizar, essas operações de báscula que subvertem um termo em seu contrário, mesmo mantendo-o, sob outros pontos-de-vista, à distância? Caberia ao mitólogo elaborar, portanto, (...) o modelo estrutural de uma lógica que não seria aquela da binaridade, do sim ou não, uma lógica outra que não a lógica do logos” (J. P. Vernant, apud Derrida 1995: 7).

É nesse sentido que a desconstrução derridiana nos desorienta, ao abrir mão de um centro, de uma origem, no que se refere à questão do pensamento. Ou seja, retornando ao objeto deste estudo, assim como uma versão contemporânea do mito grego (no caso, "Antígona") toma a origem clássica (sofocliana) como referencial, não se pode prescindir de sua atualizada 
releitura para a reconfiguração do próprio mito que, supostamente, se encontra na origem de todas as suas reinterpretações.

É na impossibilidade de lidar, crivelmente, com os valores religiosos, políticos, éticos de outrora que o artista contemporâneo - cumprindo, às avessas, o papel do mitólogo - perguntará pela vigência da mítica na visão de mundo atual, a considerar tanto suas efetivas possibilidades quanto seus intransponíveis limites. Na esteira de tal reflexão vem o questionamento acerca da matéria de que é feita a tragicidade de nossa época. Seria ela, representada no patrimônio cultural, um elo herdado dos antigos? Ou seria justo por causa dela que insistimos em volver nosso interesse para algo historicamente tão distante de nossa realidade hoje, como é o caso do repertório trágico da Atenas clássica? Obras teatrais como a realizada no Chile pelo grupo Los Mismos têm a qualidade de manter acesa a chama que alimenta essas perguntas que tanto nos assombram.

\section{Referências bibliográficas}

Candeias, Maria Lúcia, "Libelo contra a tirania", in José Simões de Almeida $\mathrm{Jr}$ (org.), Duas tábuas e uma paixão: o teatro que eu vi, São Paulo, Fundação Padre Anchieta/Imprensa Oficial, 2006, pp. 81-83.

Derrida, Jacques, Khôra, tradução de Nícia Adan Bonatti, Campinas, Papirus, 1995.

Lehmann, Hans-Thyes, Teatro pós-dramático, tradução de Pedro Süssekind, São Paulo, Cosacnaify, 2007.

Massa, Clóvis, "Poéticas de hoje e poéticas de ontem", in Fátima Saadi \& Silvana García (org.), Próximo ato: questões da teatralidade contemporânea, São Paulo, Itaú Cultural, 2008, pp. 40-47.

Nuñez, Carlinda Fragale Pate, "Força mítica e atualidade de Ismene". Texto no programa do espetáculo A tragédia de Ismene, princesa de Tebas, Rio de Janeiro, CCBB, 2007.

Sófocles, Antígona, introdução e tradução do grego de Maria Helena da Rocha Pereira, Lisboa, Fundação Calouste Gulbenkian, 2008.

CLAUDIO CASTRO FILHO 